\title{
Telephone Associated Pathology: Clinical Case Studies and Discussion
}

Mark Servis, M.D.

The New York Hospital-Cornell Medical Center, White Plains, New York

Follow this and additional works at: https://jdc.jefferson.edu/jeffjpsychiatry

Part of the Psychiatry Commons

Let us know how access to this document benefits you

\section{Recommended Citation}

Servis, M.D., Mark (1989) "Telephone Associated Pathology: Clinical Case Studies and Discussion," Jefferson Journal of Psychiatry. Vol. 7 : Iss. 2 , Article 9.

DOI: https://doi.org/10.29046/JJP.007.2.007

Available at: https://jdc.jefferson.edu/jeffjpsychiatry/vol7/iss2/9

This Article is brought to you for free and open access by the Jefferson Digital Commons. The Jefferson Digital Commons is a service of Thomas Jefferson University's Center for Teaching and Learning (CTL). The Commons is a showcase for Jefferson books and journals, peer-reviewed scholarly publications, unique historical collections from the University archives, and teaching tools. The Jefferson Digital Commons allows researchers and interested readers anywhere in the world to learn about and keep up to date with Jefferson scholarship. This article has been accepted for inclusion in Jefferson Journal of Psychiatry by an authorized administrator of the Jefferson Digital Commons. For more information, please contact: JeffersonDigitalCommons@jefferson.edu. 


\title{
Telephone Associated Pathology: Clinical Case Studies and Discussion
}

\author{
Mark Servis, M.D.
}

The advancement of modern technology shapes and develops new expressions of psychopathology and accompanying treatments. This is most apparent with the telephone, an instrument of contact and communication for the patient, and assessment and intervention for the therapist. The telephone both constrains and creates unique constellations of patient symptomatology. This paper will examine one such telephone symptom complex - the habitual overuse of the telephone by non-bipolar patients. The frequent monopolization of the phone seen in some bipolar patients will not be considered, though the elements of intrusion and aggression discussed in this paper are probably shared by manic patients.

A review of the psychiatric literature reveals a surprising paucity of writing about the psychodynamic significance of patient's use of the telephone, even in the area of sexual paraphilias and sexually obscene phone calls. Freud describes the telephone as a representation of the body, and as a metaphor for psychoanalysis $(1,2)$. Stekel $(3)$ discusses the telephone as a sexual symbol, and Harris (4) relates phobic anxiety of the telephone to castration anxiety. Fliess (5) is the first to write of telephoning as a symbol for masturbation, an idea elaborated by Shengold in his paper The Symbol of Telephoning (6). Almansi, Socarides, and others have written of the use of the telephone in sexual paraphilias $(7,8)$. The bulk of writing in the mental health literature, however, focuses on the use of the telephone in counseling services and suicide hotlines. With the ever increasing utilization of the telephone by patient and therapist alike, this limited analysis of the meaning and uses of the telephone in the psychiatric literature is an intriguing deficiency in the understanding of patient behavior.

Throughout two years of residency training in clinical psychiatry in inpatient and outpatient settings, I have treated two patients whose sole presenting complaint was the overuse or abuse of the telephone. These patients would make upwards of fifty calls a day to their parents, spouse, or therapist. This behavior was independent of manic or psychotic symptoms, and without overt sexual deviancy or perversion. Such an affinity for the telephone is not uncommon among psychiatric patients, as many psychiatrists and their secretarial staff can attest. Some possible meanings and the various expressions of this behavior will be examined in these two case studies.

Mrs. Z is a thirty-three year old, married, Jewish mother of two children who presented to the New York Hospital-Westchester Division Outpatient 
Department with a two year history of agitated depression. Her mother made the initial contact with the clinic, seeking advice in dealing with her daughter's excessive telephone use. She had been making over fifty calls a day to her mother and other family members for over a year. She would habitually ask for their advice in helping her to overcome her depressive symptoms. "I just don't know how to spend my time. If I could just be like my mother." The patient referred often to her mother in psychotherapy, with whom she had an intensely ambivalent relationship.

The patient's depression began two years previously following the termination of an unplanned pregnancy. Mrs. Z quickly developed depressive symptoms which included difficulty falling asleep, frequent crying spells, an inability to concentrate or perform usual work, passive suicidal ideation, habitual telephone use, and other agitated behavior including excessive exercise, conversation, and shopping. There was no evidence of an elated or expansive mood, little irritability, and no delusional or psychotic thinking.

The patient had been to many psychiatrists during the course of her illness, and was generally dissatisfied with their attempts at treatment. She had not apparently benefited from trials of Imipramine, Nortriptyline, Tranylcypromine, Lithium, and Carbamazepine. An extensive medical and neurological work-up, including a CT scan, EEG, and endocrine study were negative. Her previous therapists seemed exhausted by her repetitive telephone calls to their home or office. These calls would usually cluster immediately after an office visit.

Mrs. Z began weekly supportive psychotherapy in the outpatient clinic for her depression. She quickly became known by the secretarial staff for her burdensome routine of calling her therapist following every session. The patient would call over thirty times a day until firm limits around phone calls were set. If Mrs. $\mathrm{Z}$ was limited in her calls to her therapist, other family members or friends would be called in the same manner. The content of these calls always seemed superficial, with repeated requests for reassurance or incidental questions concerning her treatment.

Mrs. $\mathrm{Z}$ would also attempt to delay termination of sessions and phone calls. Two previous therapists had called the police to intervene when she would not leave their office. Family members utilized a variety of strategies to avoid Mrs. Z's harassment. Changes in phone number, answering machines, and threats to disconnect Mrs. Z's phone were all attempted with marginal success. Mrs. Z would quickly displace her daily telephone calling to other individuals, though her mother always remained the favored and primary object. Mrs. Z's depressive symptoms resolved over a nine month period, with a moderate decrease in her telephone use. Mrs. Z remained in weekly supportive psychotherapy, with a gradual normalization of her telephone use almost 18 months after her initial presentation to the outpatient clinic.

Miss F is a twenty-five year old, single, Orthodox Jewish woman who was remanded by a family court to an acute inpatient unit at New York Hospital for her telephone harassment of family members and a former teacher. During the 
six months prior to admission, Miss $\mathrm{F}$ had been calling a LSAT preparation course instructor up to sixty times a day and positioning herself in hotel lobbies where he was conducting LSAT preparation courses. These provocations resulted in efforts by the instructor to have Miss F's phone disconnected with police and telephone company assistance. In addition, Miss F was calling family members daily and attempted to contact the head of the school on numerous occasions via the telephone.

Miss F appeared depressed to her family. She was isolated, sleeping poorly, frequently tearful, and expressing suicidal ideation. There was no delusional or psychotic symptomatology, and no history of manic behavior.

After Miss F's family discovered her costly telephone bills, they consulted a psychiatrist who recommended inpatient psychiatric treatment. Following Miss F's refusal of outpatient or inpatient treatment, the family had her followed by detectives who observed her spending an entire day phoning from a hotel lobby. Miss F's family was frightened, puzzled and uncertain of how to deal with her unusual behavior. At one point Miss F was observed holding two telephone receivers, one in each hand, to her ears. She was taken by the police to Family Court, and remanded to New York Hospital for psychiatric treatment.

During Miss F's inpatient treatment, her habitual telephone use persisted until the staff enforced firm limits on her phone calls. She would call her family members, therapist, and friends at every opportunity, at times disguising her voice to get by the hospital operator. The content of these calls seemed superficial and repetitive, consisting almost entirely of questions answered on previous occasions. She resisted termination of these telephone conversations by attempting to sustain contact until the last possible moment. When her therapist and family blocked her opportunities to contact them, Miss F would switch to phoning other hospital staff and administrators. Miss $\mathrm{F}$ was unable to verbalize any insight into her continuing excessive telephone use.

Miss $\mathrm{F}$ refused medications during her two month inpatient treatment, but complied with supportive psychotherapy and other milieu treatment. Her depressive symptoms remitted, her habitual telephone use significantly decreased, and she was discharged to outpatient follow-up. In outpatient treatment Miss F demonstrated none of the pathological telephone behavior apparent both before and during her hospitalization.

These two case histories demonstrate the central symbolic and actual role which the telephone can acquire in patient psychopathology. The content of telephone communications for both patients appeared to be exceedingly superficial, and the purpose of telephoning clearly extended beyond secondary process verbal communication or any needs for clarification of information. The telephone is rich in symbolic imagery, meaning and function. It allows for instant and potentially intrusive contact, controlling and powerful manipulation, and intimate, yet distant interpersonal relations. As an example of the psychodynamic principle of multiple function, the telephone is possessed of multiple possible symbolic meanings. 
Freud described telephoning as a metaphor for psychoanalysis, instructing the analyst to "turn his own unconscious, like a receptive organ, towards the transmitting unconscious of the patient. He must adjust himself to the patient as a telephone receiver is adjusted to the transmitting microphone" (2). This analogy represents the telephone as primarily a conduit for information, essentially a communicating instrument. Freud, however, also describes a dream in which a man's telephone being out of order refers to his body and penis not working correctly (1). Shengold writes of a patient for whom the telephone appeared to be a bisexual representation of his own body, with both a sending and receiving apparatus. His handling of the telephone had, in Shengold's view become a symbolic form of masturbation (6).

The powerful attraction associated with habitual telephone use and the accompanying level of excitement apparent in both case examples is suggestive of masturbatory activity. Mrs. Z frequently described her constant need to call friends and relatives as "an addiction" saying "I can't stop." This disavowal of personal responsibility allowed Mrs. Z some relief from feelings of guilt. Both patients reported occasional periods of physical exhaustion following a frenzy of telephone calling. Freud called masturbation the "primary addiction and ... all other addictions ... only enter into life as a substitute or replacement for it" (9). Freud's use of the term "addiction" is perhaps different from our present day understanding enriched by neurobiology.

Stekel, in 1911, wrote about the sexual symbolism of the telephone in Vienna, using the example of a popular song in which terms describing the mechanics of telephoning obviously allude to details of sexual acts. He also describes a telephone dream in which the erotic nature of the phone and the phallic symbol of the transmitting voice seem evident (3). Harris, in his paper on telephone anxiety, relates phobic avoidance of the telephone to castration anxiety and sees the symbolic significance of the voice as "probably phallic" (4). Miss F's repeated phone calls to her course instructor occurred in the context of a classroom infatuation with him.

Fliess described what he felt were the sexualized elements of pathological telephoning as "a mutual stimulation of two persons." One person initiates the contact and invades, while the other is a recipient. However, Fliess suggests that the roles may be reversible during telephone conversation, with each participant having an active, intruding prosthesis and a passive, receiving one. Fliess feels that the two people usually stand for mother and child, and that "compulsive telephoning serves ... the maintenance of an identification" with the mother (5).

This symbolic function of telephoning was highly suggested by Mrs. Z's behavior. She most frequently called her own mother or mother substitutes. Her primary verbalized anxiety was a fear of failing to function as an adequate mother with her own children. Mrs. Z sought frequent reassurance, advice and instruction in how to be like her own mother. Her habitual use of the phone followed an abortion, an action she hid from her parents due to her shame. The 
telephone for Mrs. Z may have represented an adult umbilical cord to maternal objects. The chance to reenact verbal interchange with a maternal figure was powerfully attractive, and provided an apparent soothing effect.

The calming effect of telephoning for this type of habitual telephone user relates not only to eroticized activity and recreating maternal ties, but may also protect against separation anxiety and other more primitive fears. Both Mrs. Z and Miss F would have to be "pried" from the phone at times by family members due to their clinging, dependent attachment to the machine. Recipients of their phone calls would often hang up during extended conversations after repeated failure to effect more cordial terminations. Mrs. Z's refusal to leave her therapist's office on numerous occasions may indicate both her extreme fears of separation and efforts to control the therapist for aggressive reasons. Miss F described feeling "like I was going to die" when forced to terminate phone conversations. The exacerbation of telephone overuse for both patients during periods of affective illness may relate to a role of insuring against loss and maintaining contact with objects. Their clinical course and related telephone use suggests that habitual telephoning may serve as a subtle clinical clue to incipient depression in some individuals.

Shengold has suggested that in patients who are psychotic or borderline, telephoning can maintain some object ties at a bearable distance "providing separation without loss and contact without fusion" (6). Almansi presents the case of a patient who would masturbate during telephone calls to "excite women, but at a safe distance. He could be safe and sexual at the same time" (7). "Dial-a-porn" services and techniques are probably successful due to their temporary gratification of dependency and power needs in a pseudo-sexualized setting (10). Anyone familiar with adolescence recognizes the safe intimacy which the telephone can afford and its frequent use by adolescents exploring the dangerous world of intimate and sexually charged relationships. Though often providing only a "pseudo-intimacy," the telephone is also capable of facilitating genuine closeness as seen in the highly successful telephone advertising slogan "reach out and touch someone." The telephone is therefore an attractive choice for some patients struggling with more mature object relatıons. Both Mrs. Z and Miss $\mathrm{F}$ were more comfortable on the phone than in person when talking with significant others, consistent with deficiencies in their object relations.

Finally, a symbolic meaning reflected in habitual telephone use is revealed in the often strong negative countertransference to these patients. Miss $F$ was greatly disliked by the staff for her controlling and intrusive manner. Mrs. Z was resented for her telephone harassment of secretarial staff. Neither patient elicited the compassionate or understanding response afforded other psychiatric patients with debilitating behaviors. Both Mrs. Z and Miss F had constricted expressions of anger probably due in part to harsh superego elements. Mrs. Z was able to recognize hatred and jealousy of her siblings as an occasional motivating feature of her telephone contact with family members. Both sadistic and masochistic elements were evident in Miss F's telephone harassment of 
individuals. Harris has described the telephone voice as representing both a cutting instrument and the fear of "being cut off" (4). Mrs. Z would sometimes angrily hang up the phone with her therapist and family members in midsentence when her needs were not immediately addressed.

Several possible expressions and meanings of telephone use, and particularly telephone overuse, are suggested in both case examples. The management of patients exhibiting telephone associated pathology is not discussed in the psychiatric literature, leaving the development of appropriate therapeutic strategies to the clinical instinct and wisdom of the therapist. Though the phone is often overutilized by patients, the meaning of telephone behavior is underutilized by therapists. The special complexity and richness of the telephone as a metaphor makes such an inquiry challenging and potentially enriching in the understanding of our work with patients.

\section{REFERENCES}

1. Freud S: The interpretation of dreams. SE 5:297, 1900

2. Freud S: The psychopathology of everyday life. SE 6:115-116, 1912

3. Stekel W: Sex and Dreams. Boston, Badger, 1922

4. Harris, H: Telephone anxiety. J Am Psychoanal Assn 5:342-346, 1957

5. Fliess R: Symbols, Dream and Psychosis. New York, Int Univ Press, 1973

6. Shengold L: The symbol of telephoning. J Am Psychoanal Assn 30:461-470, 1982

7. Almansi R: Scopophilia and object loss. Psychoanal Quart 48:601-621, 1979

8. Socarides C: Preoedipal Origin and Psychoanalytic Therapy of Sexual Perversions. New York, Int Univ Press, 1987

9. Freud S: The Origins of Psychoanalysis: Letters, Drafts and Notes to Wilhelm Fliess. New York: Basic Books, 1954

10. Schomer J: Personal communication, 1988 